\title{
Quest for Better Technology: Case of Brown Coir Fibre Industry in Sri Lanka
}

\author{
K. V. N. N. Jayalath ${ }^{1}$, P. M. E. K. Pathiraja ${ }^{1}$, U. K. Jayasinghe-Mudalige ${ }^{2}$, \\ S. D. J. N. Subasinghe ${ }^{1}$ and W. G. P. Weerasinghe ${ }^{2}$
}

\begin{abstract}
The purpose of this study was to assess the impact of a number of attributes $(\mathrm{a}=23)$ upon 5 major factors (Labor, Land and Capital, Machine, Technical and Market) that influence a selection of a particular technology to manufacture brown coir fibre in Sri Lanka (i.e. Sri Lankan Drum Pairs, Defibering Machine, D1 Machine). A cross section of owners of fibre mills $(n=30)$ located in the Kurunegaka, Puttlam and Gampaha districts were selected and a personal interview with each mill owner was carried out with the help of a structured questionnaire from May to June 2008 to collect data. The Semantic Differential Analysis techniques were employed to find the relative strength of the attributes of 5 factors considered in the analysis, where the responses were recorded on a seven-point bipolar scale. The "XLStat" software was used extensively to plot the relationships between the 23 attributes and 3 technologies.

The results suggest that all three technologies are negatively perceived by the coir fibre millers on land and capital, and machine subsets. Further millers had negative perception on attributes related to labor subset of Sri Lankan Drum Pair technology. However, they hold the view that high quality of the bristle fibre extracted by this machine is not comparable with that extracted using any other technologies. The millers' perception on technical and market attributes of the three different technologies was better than on other attributes.

The results imply that policymakers should, more specifically, take into account the issues related to capital, machine and labor as they advise coir fibre manufactures about possible technology transfer, in order to avoid potential failures in these markets (i.e. plant-exit) and government policy (i.e. non-compliance).
\end{abstract}

Keywords: Coir fiber, Fiber Extraction, Technology Transfer, Semantic Differential.

\footnotetext{
${ }^{1}$ Coconut Research Institute, Lunuwila (61150), Sri Lanka (email: economics@cri.lk).

${ }^{2}$ Department of Agribusiness Management, Faculty of Agriculture and Plantation Management, Wayamba University of Sri Lanka, Makadura, Gonawila, Sri Lanka (email:udith@ hotmail.com).
} 


\section{Introduction}

The coir fibre industry plays a vital role in the economy of Sri Lanka by contributing nearly 0.3 percent to the Gross Domestic Product (GDP). It also provides about 40,000 employment opportunities, especially to the rural poor. The industry has contributed to the economy further by providing approximately 211 million US\$ of foreign exchange in 2007, which was about 44 percent of total export earnings in Sri Lanka from all coconut products (Coconut Development Authority, 2007).

The coconut processing industries in most producing countries has been focused traditionally on the "non-kernel" (i.e. coir fibre and shell) and the "kernel (i.e. desiccated coconut, coconut oil and copra) products. Coir fibre is, in general, categorized into two distinct groups based on the type of husk use, method of extraction, physical properties and their uses, namely: (1) white fibre - coir fibre extracted from fresh green coconut husk (few days after husking) by the manual process, and (2) brown fibre - coir fibre extracted mechanically from husk of seasoned coconuts (i.e. the coconuts are seasoned by heaping the fresh mature nuts for 3-4 weeks in the shade), being the by-product from the desiccated coconut and copra industries.

India and Sri Lanka are, globally, the major producers of coir fibre and its value-added products on a commercial basis. In Sri Lanka, the white fibre industry is characterized by a traditional, labor-intensive and largely a femaleoriented industry that is centralized in the Western and Southern Provinces, whereas the brown-fibre industry is more mechanized and export-oriented, and manufactures are concentrated in the North-Western Province primarily. Although Sri Lanka was the market leader for the processing of brown fibre in the world until 1999, India took that position thereafter. Nevertheless, Sri Lanka is still dominating in the brown fibre "trade" (i.e. 35\% of the world market share) thanks to the unique blend of colors, and rare and attractive designs associated with the Sri Lankan products (APCC, 2006).

\section{Current Technologies Used in Brown Fiber Extraction}

There are two types of milling processes used in Sri Lanka to extract brown fibre for commercial purposes, namely: (1) Wet Milling, and (2) Dry Milling. In the former, there are two different technologies, called: (a) Sri Lankan Drum Pair and (2) Defibering Machine are used extensively. In wet milling, the coconut husks are soaked for $4-6$ weeks, in order to facilitate the absorption of water, before extracting the fibre. The Sri Lankan Drum Pair (Figure 1) is a semi-mechanical method that comprises two drums - the "breaker" drum and "cleaner" drum, which are fitted with steel spikes in a wooden casing. This technology is practiced mainly to extract two types of fibres known as bristle fibre (long and coarse) and mattress fibre (short \& fine).

Figure 1. Sri Lankan Drum Pairs

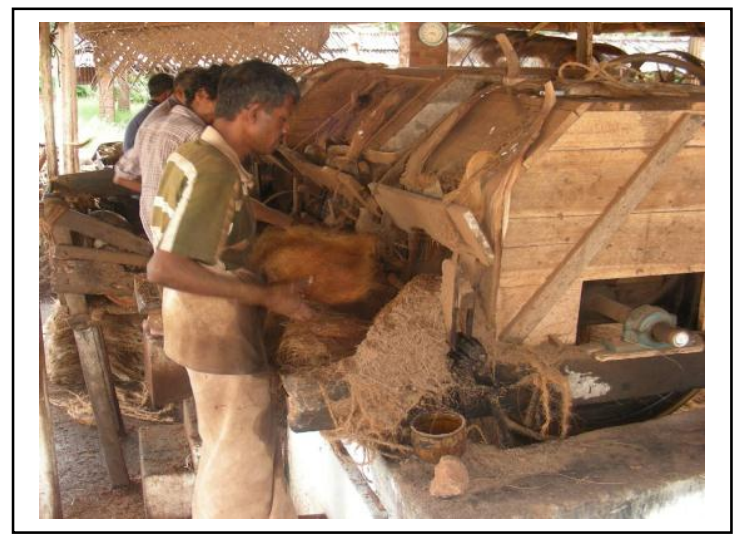

The soaked husk segments are then handfed by an operator into a rotating breaker drum, which in turn, peels off the outer skin of the husk and removes much of the short fibres and pith leaving only the long / medium - stapled and bristle fibres in the operator's hand. Next, the bristle fibre resulting from this process is hand fed against the cleaner drum to remove short -staple fibres and pith, which is collected at the bottom of the drum pairs. Finally, the fibre mixture is fed into a rotating - conical sifter so as to separate the mattress fibre from the coir fibre pith which is the by-product of coir fibre extraction. 
The Defibering Machine (Figure 2), on the other hand, is a mechanical method for brown fibre extraction. The extracted fibre is subsequently graded as bristle and mattress fibre based on length. This method is much safer from an operator's point of view, compared to the Sri Lankan Drum Pair.

Figure 2. Defibering Machine

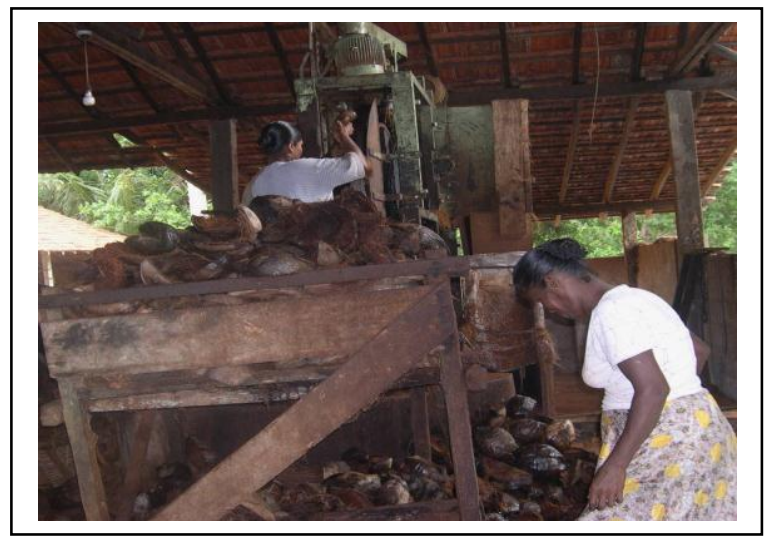

In the dry milling, brown fibre is extracted from the husk submerged in water for a period of just 2 hours, and allowed to drain for about 15 minutes. A special device called the "D1 Machine" (Figure 3) is used in this respect, which is an improved version of locally manufactured decorticator used to extract coir fibre previously.

Figure 3. D1 Machine

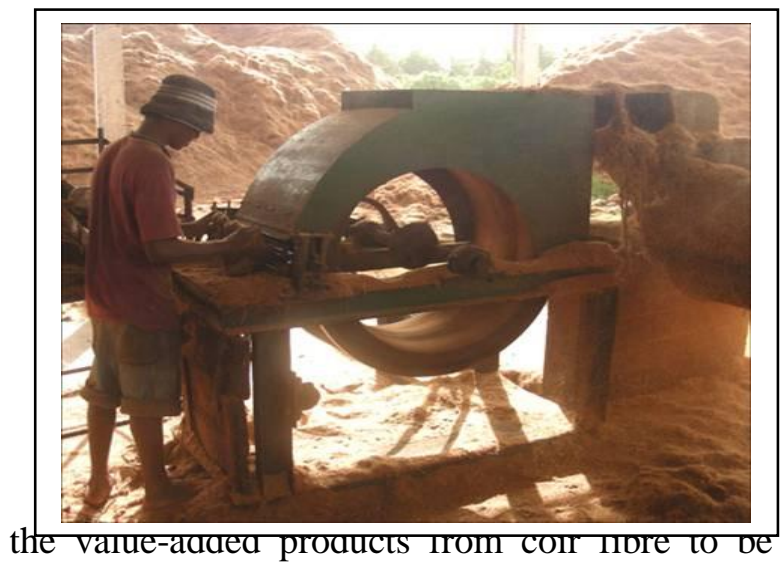

marketed both locally and globally, it has been identified that a number of problems. These include low primary productivity, high cost of production, and lack of skilled labor (Rosairo et al., 2004). Consequently, further improvements to the existing technologies have become vital to minimize the effects from such problems, especially low productivity and issues related to labor. The purpose of this study was to examine empirically the problems faced by mill owners in this industry in their efforts to improve the existing technologies in brown fibre extraction.

\section{Methods}

\section{Identification of Attributes of Technology}

As stated above, there are three technologies available currently for a miller to extract brown fiber in his/her mill, i.e.: (1) Sri Lankan Drum Pair [T1], (2) Defibering Machine [T2] and (3) D1 Machine [T3]. The millers perceptions towards a number of attributes affecting the appropriateness of these three technologies to extract brown coir fibre can be classified into 5 subsets, including: (a) Labor; (b) Land and Capital; (c) Machine; (d) Technical, and (e) Market (Table 1).

\section{Collection and Analysis of Data}

A cross section of coir fibre mills located in the Coconut Triangle of Sri Lanka (Kurunegala, Gampaha, and Puttlam districts) (n $=30$ ) were selected to collect data. Personal interviews with the owners of the mills were carried out with the help of a structured questionnaire, from May to July, 2008. A pilot testing was done by visiting several sites to confirm the issues listed as attributes.

To evaluate the extent to which an owner of a mill agreed with the phenomenon explained in each attribute classified to these 5 subsets, every statement was set to a seven point bipolar scale ranging from (+3)

Table 1. Attitude explaining the appropriateness of a technology

\begin{tabular}{|l|l|}
\hline \multicolumn{1}{|c|}{ Subsets } & \multicolumn{1}{c|}{ Attributes } \\
\hline 1. Labor & 1.1 Number required to operate the machine \\
& 1.2 Skilled labor requirement
\end{tabular}




\begin{tabular}{|c|c|}
\hline & $\begin{array}{l}\text { 1.3 Safety for laborers } \\
\text { 1.4 Labor willingness to work } \\
\text { 1.5 Labor efficiency in each technology }\end{array}$ \\
\hline 2. Land and Capital & $\begin{array}{l}\text { 2.1 Land area needed for the technology } \\
\text { 2.2 Initial capital } \\
\text { 2.3 Subsidies available } \\
\text { 2.4 Credit scheme }\end{array}$ \\
\hline 3. Machine & $\begin{array}{l}\text { 3.1 Power consumption } \\
\text { 3.2 Machine efficiency } \\
\text { 3.3 Productivity } \\
\text { 3.4 Product quality } \\
\text { 3.5 Husk soaking period } \\
\text { 3.6 Husk rejection rate } \\
\text { 3.7 By-product quantity }\end{array}$ \\
\hline 4. Technical & $\begin{array}{l}\text { 4.1 Technical assistance for installation } \\
\text { 4.2 Technical assistance for repair and maintenance } \\
\text { 4.3 Repair and maintenance } \\
\text { 4.4 Availability of spare parts } \\
\text { 4.5 Frequency of repair }\end{array}$ \\
\hline 5. Market & $\begin{array}{l}\text { 5.1 Market demand } \\
\text { 5.2 Market price }\end{array}$ \\
\hline
\end{tabular}

"extremely good" to (-3) "extremely bad". The scores given by respondents' (mill owners) on these statements $(n=23)$ were examined using the Semantic Differential Analysis (SD) techniques (Barclay arid Thumin, 1963; Osgood et al. 1957).

The SD measures a person's reactions to stimulus words and concepts in terms of ratings on bipolar scales defined with contrasting adjectives at each end. Bipolar adjective scales are a simple and economical means for obtaining data on people's reactions. Such scales, with adaptations, can be used with adults or children and persons from any culture, for attitude measurements.

\section{Results and discussion}

\section{Descriptive Statistics of the Sample}

More than 37 per cent of the sample uses the Sri Lankan drum pair technology for fibre extraction (Figure 4). The usage of Defibering Machine and D1 Machine was 35 and 27 per cent of the total sample respectively. The use of Sri Lankan Drum Pair is highest in Puttlam district while lowest in Gampaha district. The Defibering Machine was the highly adopted technology for coir fibre exaction in Gampaha district.

\section{Effect of each Subset on the Technology}

Mean and standard deviation for each individual attribute of three different fibre extraction technologies were calculated (Table 2). Labor requirement is lowest for the D1 Machine and highest for the Sri Lankan Drum Pair. The semantic differential charts explain each attribute in detail and discussion is shown below under each subset.

\section{Impact of Labor on Technology}

All five attributes considered under the labor subset gained the lowest perception of coir millers with regard to Sri Lankan Drum Pair technology (Figure 5). Skilled labor requirement is highest for the Sri Lankan Drum Pair, and lowest for the D1 Machine. Scarcity of skilled 
labor has compelled the miller to shift to other technologies. Millers' perception for safety of workers is highest towards the D1 Machine and lowest for the Sri Lankan Drum Pair. The special feature of Defibering and D1 Machine is that the operations of these machines are not gender specific.

\section{Impact of Land and Capital on Technology}

The D1 Machine requires less land area (Figure 6) than other two technologies because of the compact nature of the machine. Initial capital is lowest for the Sri Lankan Drum Pair as it is fabricated locally and highest for the Defibering Machine since it was imported from India. Subsidies and credit facilities are hardly available for coir fibre millers. This is one of the major reasons for coir fibre millers to adopt less effective and less expensive existing technologies rather than shifting to new technology which requires higher capital investment.

\section{Impact of Machine Subset on Technology}

Impact of machinery characteristics on technology (Figure 7), millers are in favour of the Sri Lankan Drum Pair for its low power consumption and high product quality. However, millers are in the view that productivity of the Sri Lankan Drum Pair is the lowest among these three technologies. The productivity and machine efficiency was highest in the Defibering Machine. Even though the Defibering Machine extracts bristle fibre, its quality in terms of length and strength is far behind that from the Sri Lankan Drum Pair. This is the reason for coir fibre millers to use Sri Lankan Drum Pair for bristle fibre extraction irrespective of its low productivity. The husk rejection rate is also higher with the Sri Lankan Drum Pair technology than with the other two technologies. Small sized husks and husks damaged due to mite infestation could not be used for fibre extraction in the Sri Lankan Drum Pair technology.

The millers' perception on the key attributes i.e. power consumption, productivity and product quality, and husk rejection rate is more or less similar in Defibering and D1 Machines. The husks that are to be used for fibre extraction in both the Sri Lankan Drum Pair and Defibering Machines needed to be soaked in water for a longer period. Therefore, millers' perception prefers the D1 Machine where husks need not to be soaked for a long time.

The quantity of coir fiber pith produced during the fibre extraction process is also an important attribute because of the increasing demand for coir fibre pith. Coir fibre pith is used for coir briquetting and various other coir fibre pith-based products. These products have a high demand and value in the export market, which in turn boosts the price in the domestic market. Since the D1 Machine produces a higher amount of coir fibre pith the respondents get a greater income from this.

On the other hand the moisture content in coir fibre pith extracted by the D1 Machine is very much lower than the other two technologies. Therefore, to the desired moisture content of $15 \%-18 \%$ can be achieved within a short period of time, reducing the cost of drying.

\section{Impact of Technical Subset of the Machine on Technology}

The semantic differential chart for technical subset (Figure 8) showed that Sri Lankan Drum Pair achieved the highest

Table 2. Mean and Standard Deviation for attributes of three different fibre extraction technologies

\begin{tabular}{|l|cccccc|}
\hline \multirow{1}{*}{ Attribute } & \multicolumn{3}{|c}{ T1 } & \multicolumn{2}{c}{ T2 } & \multicolumn{2}{c|}{ T3 } \\
\cline { 2 - 7 } & Mean & SD & Mean & SD & Mean & SD \\
\hline 1. Labor & & & & & & \\
1.1 Number of laborers & 1.19 & 0.55 & -0.15 & 1.57 & 1.42 & 0.793 \\
1.2 Skilled labor & -3.00 & 0.00 & 0.46 & 1.98 & 1.33 & 2.27
\end{tabular}




\begin{tabular}{|l|cccccc|} 
1.3 Safety for laborers & -0.94 & 1.94 & 2.9 & 0.28 & 1.42 & 2.06 \\
1.4 Labor willingness to work & -1.25 & 1.65 & 2.08 & 1.19 & 2.33 & 1.23 \\
1.5 Labor efficiency & 0.06 & 1.91 & 2.85 & 0.37 & 2.75 & 0.45 \\
\hline 2. Land and Capital & & & & & & \\
2.1 Land area & 0.69 & 2.02 & 1.15 & 1.86 & 2.08 & 0.90 \\
2.2 Initial capital & 2.31 & 1.25 & -1.08 & 1.75 & 0.08 & 1.78 \\
2.3 Subsidies available & -0.06 & 0.25 & 0.08 & 1.55 & 0.00 & 0.00 \\
2.4 Credit scheme & 0.62 & 1.36 & 0.46 & 1.94 & 0.50 & 0.90 \\
\hline 3. Machine & & & & & & \\
3.1 Power consumption & 2.53 & 0.74 & -1.75 & 2.09 & -2.00 & 0.74 \\
3.2 Machine efficiency & 0.93 & 1.94 & 2.46 & 0.66 & 1.45 & 1.37 \\
3.3 Productivity & -1.27 & 1.44 & 1.33 & 1.50 & 1.00 & 1.13 \\
3.4 Product quality & 2.94 & 0.25 & 1.77 & 1.36 & 1.42 & 1.08 \\
3.5 Husk soaking period & -1.4 & 2.66 & -1.46 & 1.61 & 0.58 & 2.23 \\
3.6 Husk rejection rate & -2.06 & 1.73 & -0.31 & 1.60 & -0.25 & 0.87 \\
3.7 By-product quantity & 0.36 & 2.13 & 0.91 & 2.02 & 1.83 & 1.19 \\
\hline 4. Technical attribute & & & & & & \\
4.1 Technical assistance: installation & 2.94 & 0.25 & 2.15 & 0.67 & 2.00 & 1.70 \\
4.2 Technical assistance: repair and & 2.94 & 0.25 & 2.00 & 1.68 & 2.58 & 0.67 \\
$\quad$ maintenance & 2.67 & 0.70 & 1.69 & 1.65 & 1.67 & 2.27 \\
4.3 Repair and maintenance & 2.94 & 0.25 & 1.85 & 0.80 & 2.58 & 0.51 \\
4.4 Availability of spare parts & 0.75 & 2.52 & -0.15 & 1.14 & -0.4 & 2.15 \\
4.5 Frequency of repair & & & & & & \\
\hline 5. Market & 3.00 & 0.00 & 2.00 & 1.29 & 1.75 & 1.420 \\
5.1 Market demand & 2.93 & 0.26 & 2.33 & 0.65 & 0.67 & 1.61 \\
5.2 Market price & & & & & & \\
\hline \hline
\end{tabular}

Note: SD stands for standard deviation.

Figure 4. Adoption of fibre extraction technologies

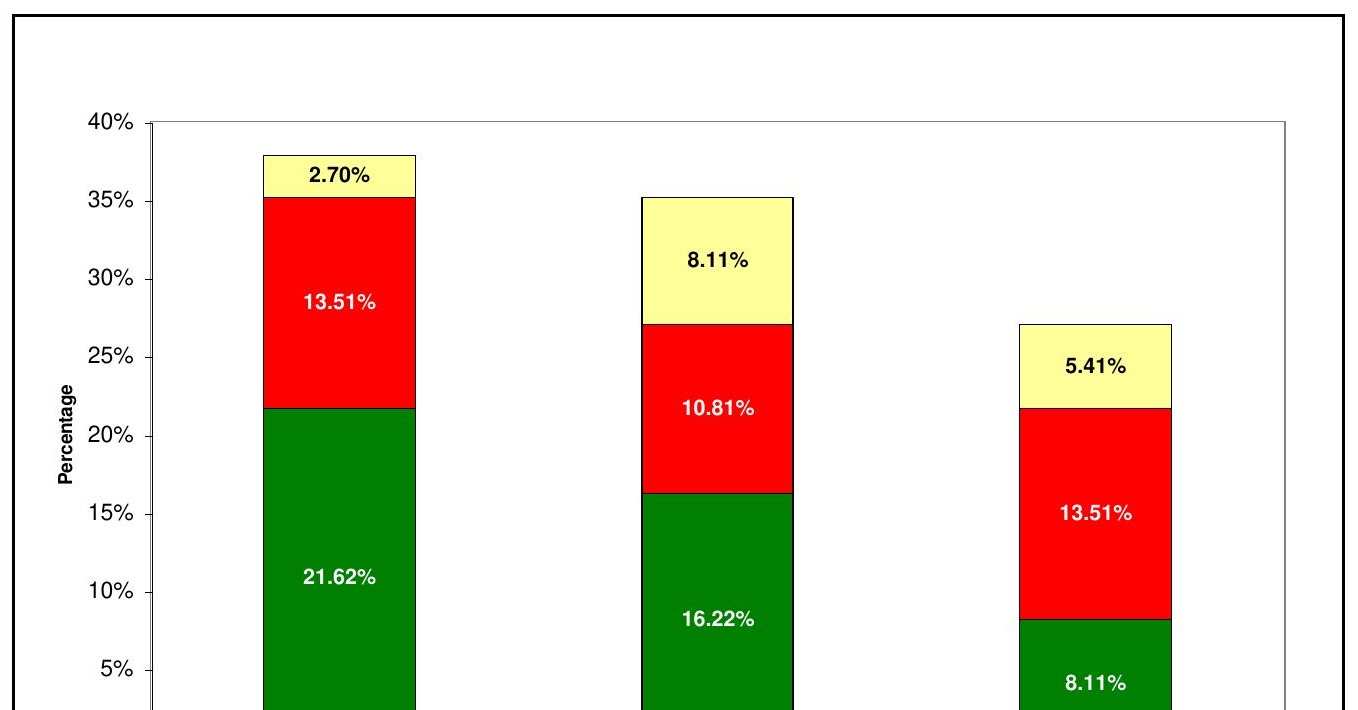


Figure 5. Semantic differential chart for labor subset

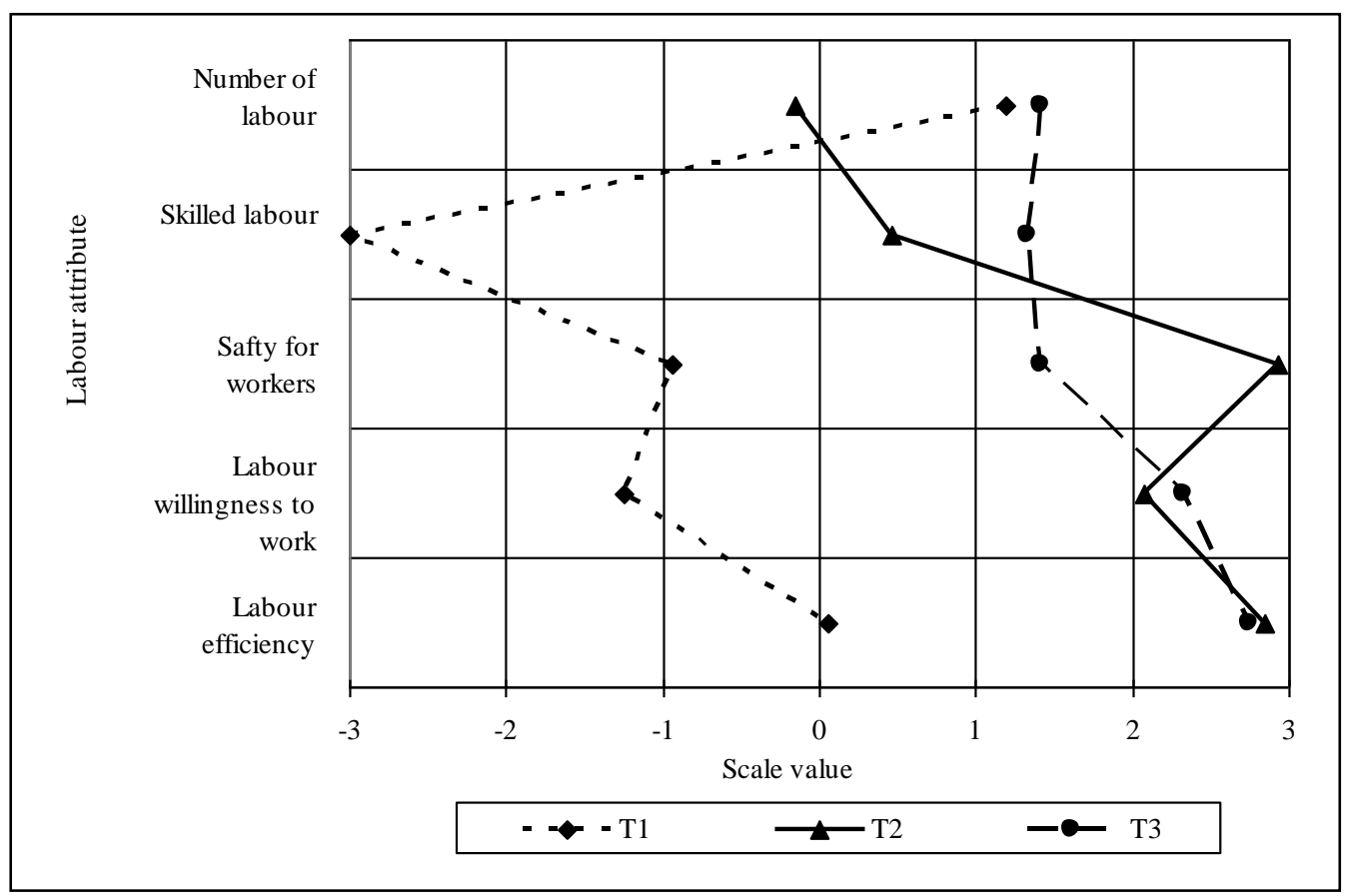

Figure 6. Semantic differential chart for land and capital subset

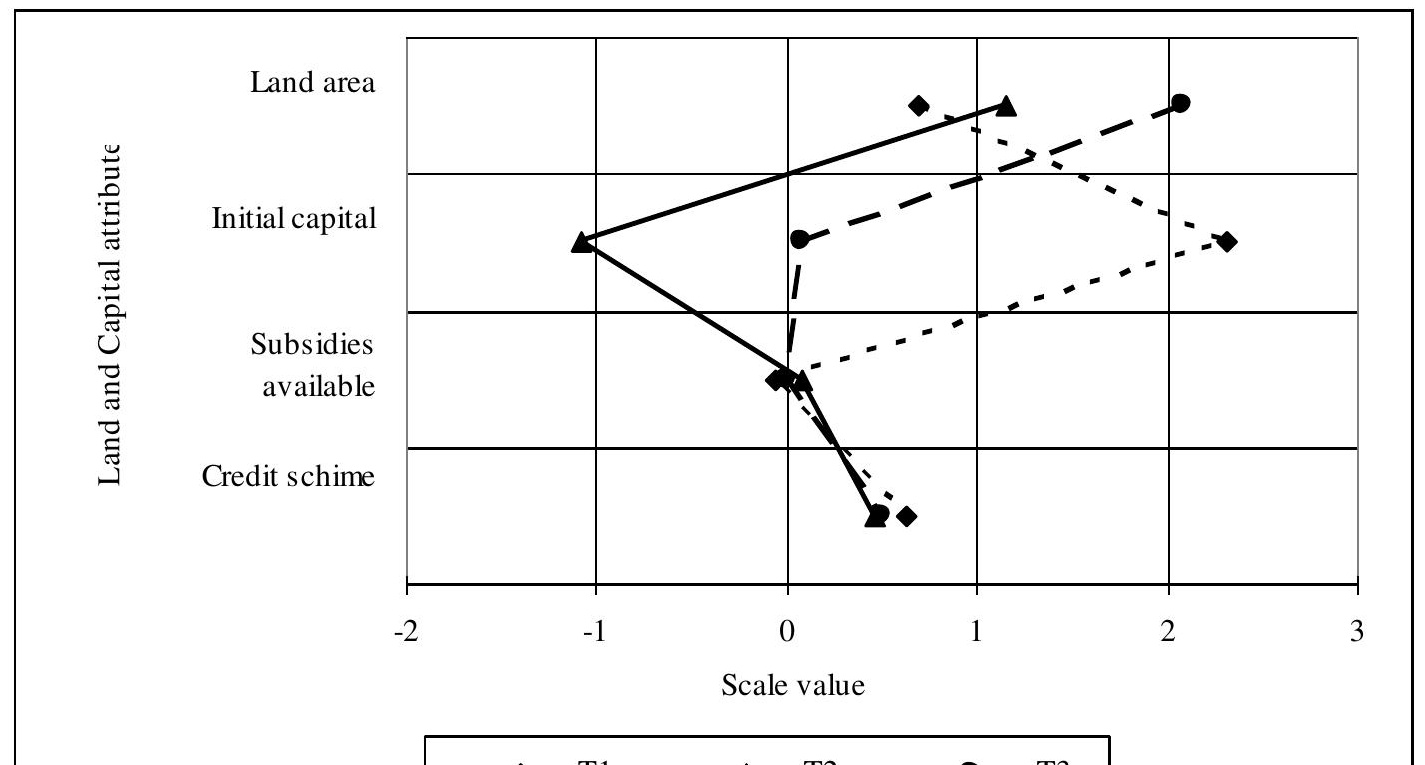


Figure 7. Semantic differential chart for machine subset

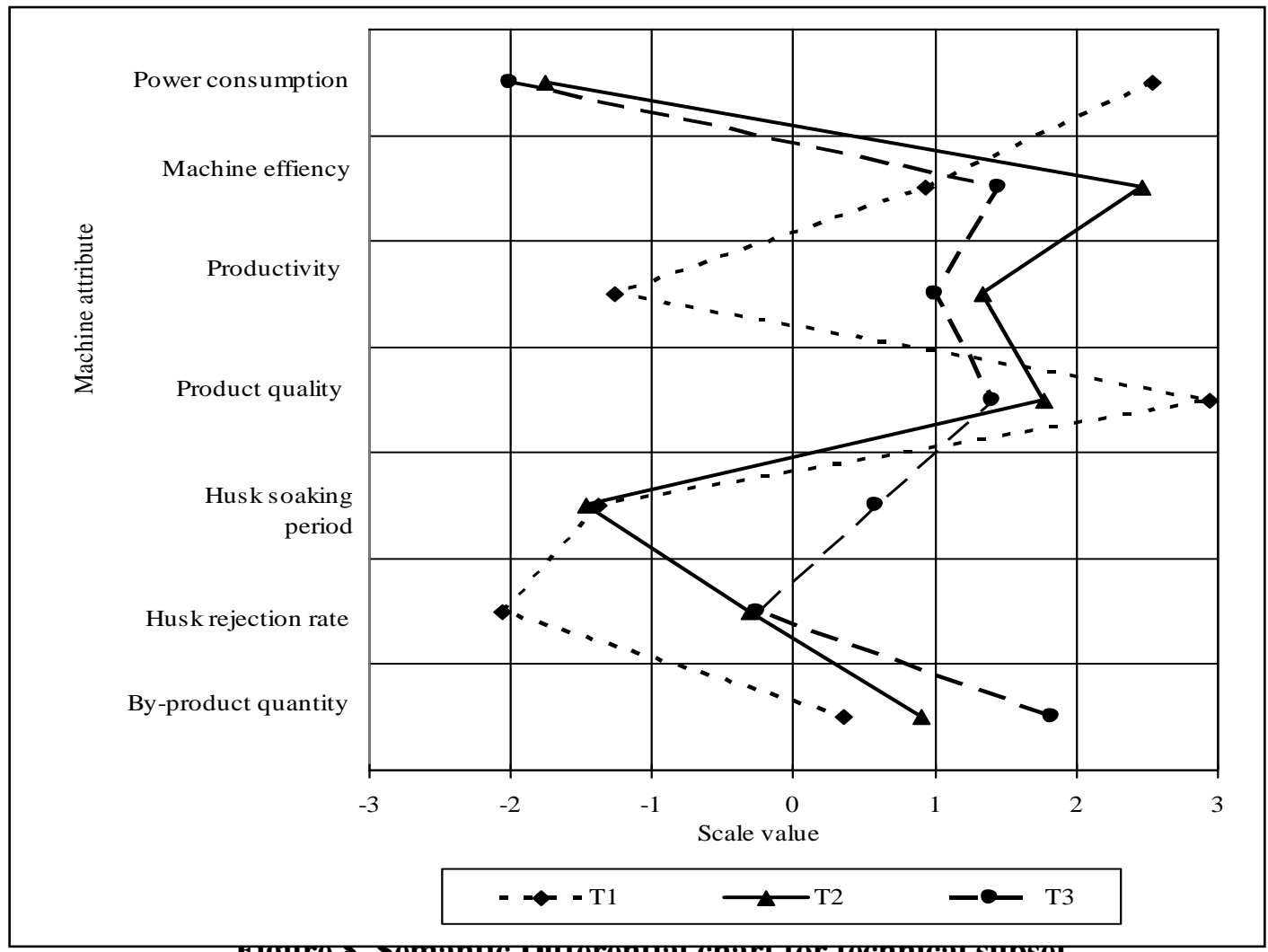

Figure o. Semtantic Dinterentral chart tor tecnmical sudset

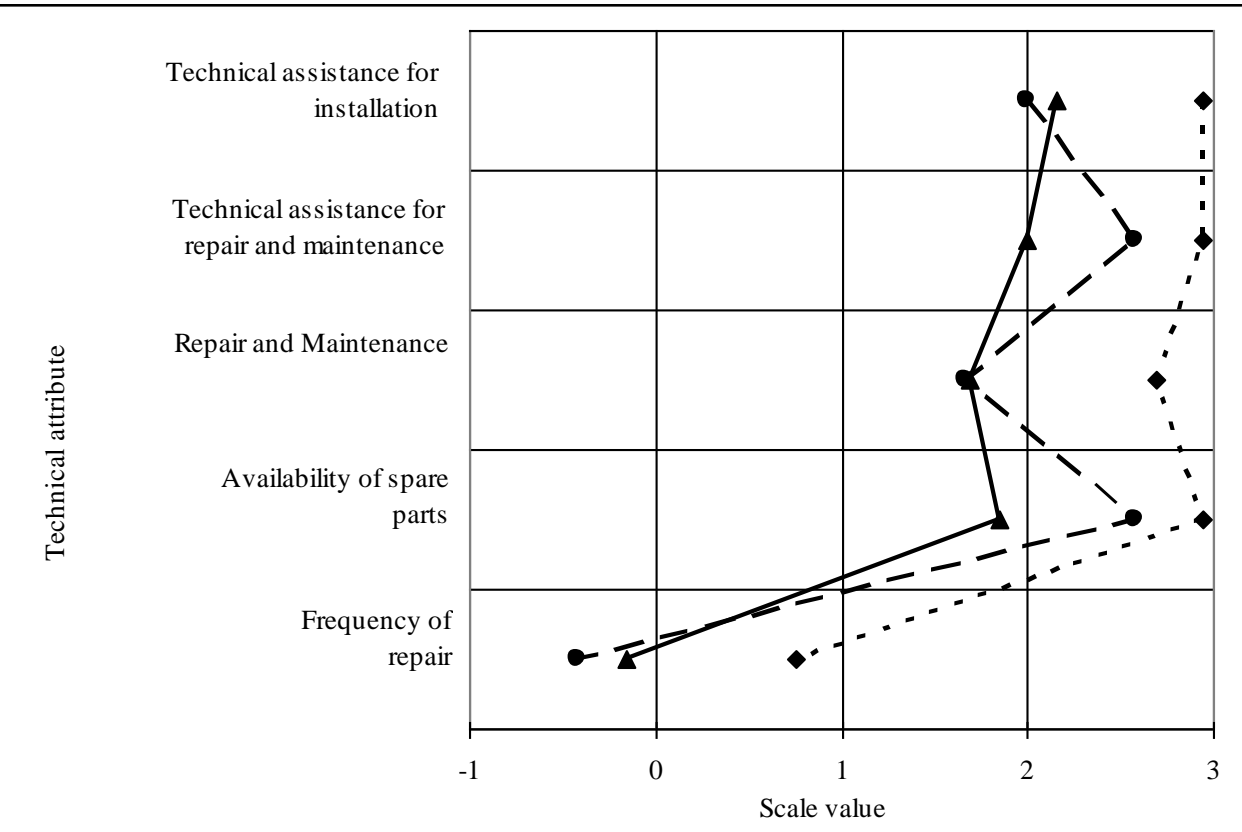


Cord 2009, 25 (2)

Figure 9. Semantic differential chart for market subset

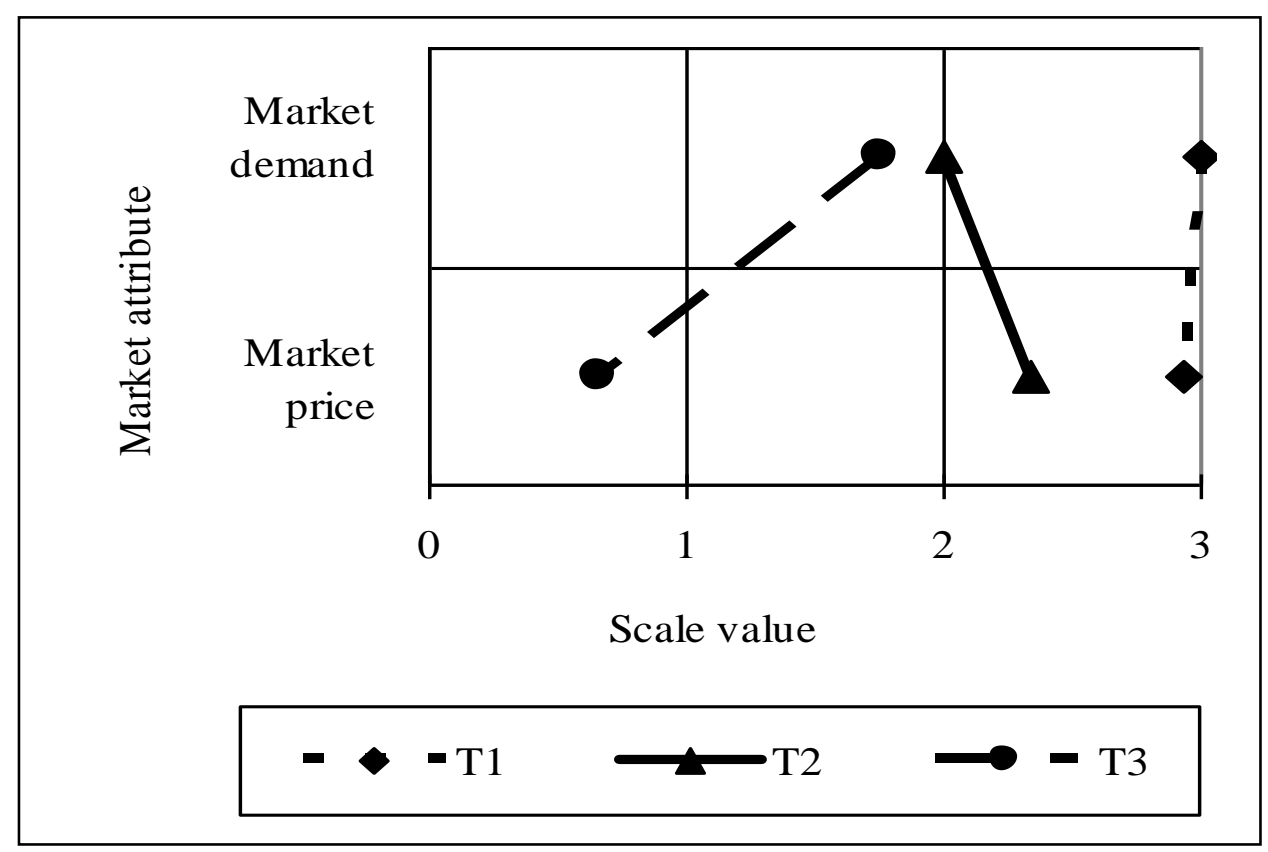

respondent's perception for all the attributes except frequency of repairs with scale value closer to three (extremely good). This is because the machine has been locally fabricated since the beginning of the industry in Sri Lanka. Therefore, installation and maintenance of the machine is comparatively easier. The Defibering Machine had the lowest miller's approval for every technical attribute. Although there are some advantages of the Defibering Machine over the Sri Lankan Drum Pair machine, millers had reverted to the Sri Lankan Drum Pair machine due to its technical attributes.

Impact of Market Subset
The semantic differential chart for market subset (Figure 9) showed that the Sri Lankan Drum Pair machine had the highest respondents' perception for both market demand and market price of the product. Brown fiber trade is dominated by Sri Lanka because of this unique quality of the bristle fibre extracted from Sri Lankan Drum Pairs. D1 Machine had the lowest perception for these two attributes among the three technologies. However, fibre extracted from the D1 Machine was in good demand as indicated by the average scale value closer to two (moderately good).

Image comparison of three technologies 
In labor attribute, (Table 3) only the Sri Lankan Drum Pair had a negative image; the other two machines had a positive image. All three technologies had a negative image for land and capital attributes and machine attributes. Technical and market attributes had a positive image for all the technologies.

Table 3. Millers' image of three different fibre extraction machinery technologies

\begin{tabular}{|l|ccc|}
\hline \multicolumn{1}{|c|}{$\begin{array}{c}\text { Machinery } \\
\text { Attributes }\end{array}$} & $\begin{array}{c}\text { Sri Lankan } \\
\text { Drum Pair }\end{array}$ & $\begin{array}{c}\text { Defibering } \\
\text { Machine }\end{array}$ & D1 Machine \\
\hline Labor & - & + & + \\
Land, and Capital & - & - & - \\
Machine & - & - & - \\
Technical & + & + & + \\
Market & + & + & + \\
\hline
\end{tabular}

Note: Scale value greater than or equal to one (slightly good) had been marked as plus (+) and other was negative (-).

\section{Conclusions and Policy Implications}

This study explored the coir fiber millers' perception on technology adoption, providing an important source of information for further technological improvement.

Although the Sri Lankan Drum Pair technology was negatively perceived by millers regarding labor subset, this was the sole technology to produce superior quality of bristle fibre. Hence, millers are reluctant to shift from this technology. However, the unsatisfactory level of productivity achieved by the Sri Lankan Drum Pair technology increased the production cost and reduced the profit margin. Therefore, introduction of an improved technology to overcome the issues related to labor and low productivity of Sri Lankan Drum Pair technology is important.

Initial capital is one of the major obstacles for millers when they are shifting to another technology. However, the lack of a financial support system in the coir fibre industry indicates a need of government intervention to introduce credit that would enable millers to shift to new technology and improve the future prospects of this industry.

\section{Acknowledgements}

The authors wish to express their gratitude to Dr. (Mrs) C. Jayasekera, Director, Coconut Research Institute of Sri Lanka for providing approval to publish this paper and Mr. J. M. D. T. Everard, Deputy Director (Research), Coconut Research Institute of Sri Lanka for his valuable comments. Deep appreciation is extended to the all respondents for their kind cooperation to make this study a success. Authors also wish to thank Mr. Ashoka Kumara, Technology Transfer Division, Coconut Research Institute of Sri Lanka for his support in this study.

\section{References}

APCC Statistical Year Book, 2006. Asian Pacific Coconut Community, Jakarta.

Barclay, A., and Thumin, F. J. (1963). Amodified semantic differential approach to attitudinal assessment. Journal of Clinical Psychology 19: 376 - 378.

Osgood, C. E., Tannenbaum, P. H., and Suci, G. J. (1957). The Measurement of Meaning. University of Illinois Press, Urbana.

Rosairo, H. S. R., Kawamura, T., and Sajeewani, T. L. G. (2004). The coir fiber industry in Sri Lanka: Reason for its decline and possible turnaround strategies. Agribusiness 20: 495 - 516.

Sri Lanka Coconut Statistics, 2007. Coconut Development Authority, Colombo.

XLStat, statistical software for Ms Excel. Online available from: http://www.xlstat.com/en/home, (Accessed 23 June 2008). 